\title{
Moving Sustainable Consumption from Hype to Reality Through the Value Chain
}

\author{
Gopalkrishnan R. Iyer and Sandra Rothenberger
}

\begin{abstract}
With apparently increasing demand from consumers for environmentally sustainable products, several firms have adopted a green positioning strategy and have attempted to develop green products, along with a distinct marketing emphasis to attract "green consumers." Researchers have long emphasized that environmentally sustainable objectives not only contribute to profits, but also strengthen the firm's competitive position (Lovins et al. 1999; Menon and Menon 1997; Porter and van der Linde 1995; Schmidheiny 1992). Thus, received wisdom now appears to suggest that it is very much possible for firms to pursue the trifecta of environmental sustainability, profits, and competitive advantage. And, in recent times, the goals of sustainability are stated to be an imperative that organizations simply cannot ignore; as Nidumolu et al. (2009) argue, sustainability is "a mother lode of organizational and technological innovations" that would redefine the competitive landscape with new business models and new practices (p. 57). However, despite scholarly consensus and confidence on the profitability of environmentally sustainable strategies, green marketing practices are still not widely accepted or embraced in all industries. In this chapter, we develop a framework for the examination of the vital role of the supply chain, especially the retail sector, in implementing the sustainability objectives of companies. We argue that environmental sustainability in the value chain, especially through the three tenets of reduce, recycle, and reuse, is quite feasible and economical.
\end{abstract}

References available upon request.

\footnotetext{
G.R. Iyer $(\bowtie)$

Florida Atlantic University, Boca Raton, FL, USA

e-mail: giyer@fau.edu
}

\section{S. Rothenberger}

Solvay Brussels School of Economics \& Management, Brussels, Belgium

e-mail: Sandra.rothenberger@ulb.ac.be 